\title{
COMENTÁRIOS DE LEITORES NA INTERNET E A AXIOLOGIA DO IDIOTA
}

\section{COMMENTS FROM INTERNET READERS AND THE AXIOLOGY OF THE IDIOT}

Carlos Alberto de Carvalho*

Moisés Lemos Martins**

\section{RESUMO:}

A partir de comentários de leitores sobre notícias publicadas em sítios noticiosos do Brasil e de Portugal relativas a crimes de proximidade contra mulheres, tentamos entender, a partir dos estudos acerca das relações de gênero, qual seria, afinal, a natureza do idiota que ganha a palavra, segundo a proposição de Umberto Eco, num sítio (a internet) que somente ele pode dar a tal figura o privilégio de ser lido. Para alcançar nossos objetivos, propomos pensar o idiota tendo como referência seus modos axiológicos próprios, o que requer, em primeiro lugar, entender tal categoria de pessoas. $\mathrm{Na}$ sequência, analisamos alguns comentários de leitores, expressos na internet, que nos parecem típicos do idiota.

\section{PALAVRAS-CHAVE:}

Comentários de leitores, Idiota, Crimes contra mulheres.

\section{ABSTRACT}

Based on the contributions of gender studies and Umberto Eco's propositions, this article aims to understand the nature of the idiot who gains the word within the sole environment that can give such a figure the privilege of being read - the internet. For that, we used comments from readers on news stories regarding crimes against women published in news websites in Brazil and Portugal. With the aim of understanding the nature of this figure, we though the idiot from its own axiological modes, which requires the understanding of such a category of people. Then, we analyzed the comments from some internet readers that seem to us typical of the idiot.

\section{KEYWORDS:}

Readers' comments, Idiot, Crimes against women.

* Professor do Departamento de Comunicação Social da Universidade Federal de Minas Gerais, com atuação na graduação e na pós-graduação. Coordena o Insurgente: Grupo de Pesquisa em Comunicação, Redes Textuais e Relações de Poder/Saber. Bolsista Produtividade PQ2 do CNPq. E-mail: carloscarvalho0209@gmail.com

** Professor Catedrático do Departamento de Ciências da Comunicação da Universidade do Minho e diretor do Centro de Estudos de Comunicação e Sociedade (CECS), que fundou em 2001. É diretor das revistas Comunicação e Sociedade e Revista Lusófona de Estudos Culturais (RLEC). E-mail: moisesm@ics.uminho.pt 


\section{INTRODUÇÃO}

Em entrevista ao jornal português Diário de Notícias, à pergunta se consideraria ser necessário controlar a internet, Umberto Eco responde que

Isso é uma situação impossível de fazer nos tempos em que vivemos, o que se deve é ponderar o que fazer desse universo. Há quem já tenha dito, e acho que tem razão, que se nos anos 1940 houvesse internet não teria havido campos de concentração como o de Auschwitz porque toda a gente teria tido conhecimento. No entanto, no momento em que todos têm direito à palavra na internet damo-la aos idiotas, que de outro modo nunca seriam lidos noutro sítio (ECO, 2015, p. 6).

Se o raciocínio de Umberto Eco equivale ou não àquele segundo o qual sem os jornais a Revolução Francesa poderia até ter existido, mas certamente com outras características, é uma indagação pertinente. À medida que as duas crenças atribuem à comunicação, em suas mais variadas formas, capacidades de transformações socioculturais e políticas cuja complexidade exige ainda trilhar caminhos teóricos e metodológicos para que seja possível retirar alguma conclusão - em especial quando tais sugestões indicam perspectivas de poder unilateral dos media sobre pessoas e sociedades. É preciso considerar que tomar conhecimento de uma atrocidade e agir para evitá-la não constitui necessariamente atos contínuos, com ou sem o contributo dos media.

No entanto, é possível fazer uma pergunta a partir da resposta, certamente incômoda: a internet não poderia, se existisse à época do nazismo, ter contribuído para a legitimidade de atrocidades como os campos de concentração e extermínio? Tanto a crença compartilhada por Eco, quanto a hipótese de outra configuração da Revolução Francesa, naturalmente, não podem ser objetivamente respondidas, posto que especulam em torno da possibilidade de que aqueles acontecimentos pudessem ter desdobramentos distintos dos que tiveram. Outra pergunta, também incômoda, refere-se à última parte da resposta de Umberto Eco. Ele consideraria que a figura do idiota seria uma categoria de pessoas só existentes em nosso tempo? Ou, ainda desdobrando a indagação: não foram idiotas todas as pessoas que promoveram e/ou defenderam o terror e o sombrio representado pelo nazismo?

De modo simplificador, podemos afirmar que o idiota é uma categoria de pessoas de todos os tempos. Entretanto, é preciso não encerrar por aqui as possibilidades de usar a resposta de Umberto Eco para refletirmos sobre a circulação de pessoas e ideias pela internet. Se temos em conta que a sociedade pré-nazista não parece ter sido habitada 
por pessoas menos idiotas do que as nossas contemporâneas, com a possibilidade mesmo do inverso, propor num momento que a internet, se existisse naquele período, poderia ter sido fator de controle dos horrores de Auschwitz e, simultaneamente, afirmar que a internet que de fato existe dá a oportunidade da palavra a idiotas é um exercício intelectual contraditório. Tendo como pano de fundo a provocação de Umberto Eco, que nos serve mais como ponto de partida do que propriamente como exercício intelectual do qual possamos retirar consequências teóricas nos próprios termos indicados por ele na resposta, propomos investigar como a categoria do idiota é heuristicamente produtiva para a compreensão de comentários de leitores na internet.

Cuidemos, assim, de nos aproximarmos de cada uma dessas questões, que encerram problemas de ordem ética trazidas à cena pelas complexas relações que a internet trouxe ao campo de estudos da comunicação. A partir de comentários de leitores sobre notícias publicadas em sítios noticiosos do Brasil e de Portugal relativas a crimes de proximidade contra mulheres, no âmbito das contribuições dos estudos acerca das relações de gênero, tentaremos entender qual seria, afinal, a natureza do idiota que ganha a palavra, na proposição de Umberto Eco, num sítio que dá a tal figura o privilégio de ser lido.

De quem falamos quando nos referimos ao idiota? Permitir-lhe a palavra pela internet é mérito de um dispositivo dos media mais aberto do que os demais, é a banalização da idiotice ou a indicação da necessidade de limites a quem e ao que escrevem as pessoas na internet? O desafio é compreender teoricamente o que seria o idiota, assim como a ambiência contemporânea na qual ele viceja e que indica outras características de tempos contraditórios, nos quais forças sociais antagonizam quanto a princípios éticos, morais, de direitos humanos, de liberdade de expressão e do direito à informação plural e destituída de ódios, preconceitos e demais formas desmerecedoras do humano e da diversidade que o constitui.

Antes de avançarmos, frisamos que, à época em que Umberto Eco fez as afirmações acerca do idiota ocupando espaços na internet, diversas foram as reações contrárias à sua análise, considerada arrogante, elitista e preconceituosa. Em um curto artigo no sítio do Observatório da Imprensa, o professor Manuel Carlos Chaparro afirma:

Em crescendo crítico, Eco amplificou as suas já conhecidas restrições às tecnologias da informação. Mas com imprudências semânticas preconceituosas e ofensivas que não se esperariam de um especialista em semiótica e teoria do discurso (CHAPARRO, 2015). 
Diversas outras vozes críticas consideraram infelizes as declarações de Umberto Eco, mas, passados alguns anos, o espraiamento de fake news e, particularmente, de discursos de ódio na internet levou a reavaliações sobre a fala do pensador. Paulo Silvestre, palestrante e consultor de media, resume algumas dessas reavaliações:

Não sei se existe um prazo para pedir desculpas, mas espero que esses cinco anos caibam dentro dele. Umberto Eco estava certo: a Internet promoveu os idiotas da aldeia a portadores de verdade (SILVESTRE, 2020).

O ambiente tóxico da internet, particularmente nos espaços dedicados aos comentários de leitores, tem recebido crescente atenção em pesquisas de campos diversos, como comunicação, ética, direito, sociologia etc.

\section{O IDIOTA: DA IDIOTIA À IDIOTICE}

Embora o senso comum atribua valores exclusivamente negativos ao idiota, tipo humano destituído de capacidades intelectuais e outros atributos depreciativos de que não seriam portadores os não idiotas, é necessário deixar de lado a tentação de apressar as conclusões acerca dessa categoria existencial. Estudos filosóficos e teológicos têm se ocupado do idiota como um tipo, nos dizeres de Friedrich Nietzsche, portador de uma conformação psicológica cujas particularidades abrem caminhos para pensar a dimensão axiológica dessa figura, algo talvez raro na história da humanidade, em uma das suas formas de existência. Em 0 anticristo, Nietzsche busca no Jesus histórico, em contraposição ao Jesus dos evangelhos, compreender os motivos que levaram o cristianismo a assumir características que ele considera contrárias ao que seria a vida do Salvador.

O que me interessa é o tipo psicológico do Salvador. Este poderia estar contido nos Evangelhos a despeito dos Evangelhos, por mais mutilado ou sobrecarregado que esteja com traços estranhos: tal como o de Francisco de Assis se conserva nas suas lendas, não obstante as suas lendas. Não interessa a verdade sobre o que ele fez, sobre o que disse, sobre o modo como morreu, mas a questão é saber se ainda nos é possível imaginar o seu tipo em geral, se ele foi "conservado pela tradição"? (NIETZSCHE, [20--?], p. 29).

É na esteira dessas indagações que Renato Nunes Bittencourt desenvolve a ideia de que Friedrich Nietzsche defende no $\mathrm{O}$ anticristo a tese de que Jesus constituiu um autêntico idiota, acepção que nada tem a ver com os valores negativos atribuídos a essa categoria humana pelo senso comum. 0 idiota nietzschiano inaugura as possibilidades de 
investigação acerca da idiotia, noção cujas implicações no campo das reflexões éticas, políticas e morais são profícuas para lidar com a perspectiva dos comentaristas idiotas da internet nos termos propostos por Umberto Eco. Como adiante se desenvolverá, a noção de Eco nos leva a uma outra dimensão axiológica, também ela promissora para reflexões éticas, políticas e morais, situadas, no entanto, noutro polo axiológico, o da idiotice, sobrecarregada, desde sempre, de valores negativos e indicadora de uma classe de pessoas destituídas das características da idiotia. Mas, afinal, do que trata a idiotia de Jesus? Segundo Bittencourt,

Este seria um "idiota”, não na sua depreciativa conotação usual do senso comum, mas no sentido original do termo grego, ou seja, de uma pessoa indiferente aos valores estabelecidos usualmente pela sociedade, pela civilização, pela coletividade humana, por não compactuar com as circunstâncias que envolvem a realidade cotidiana (BITTENCOURT, 2011b, p. 108).

Em sua condição amoral de negação dos valores, modas e tradições de uma determinada sociedade, o idiota é uma pessoa devotada a uma vida introspectiva, que, contrariamente ao que à primeira vista a amoralidade poderia sugerir, vive segundo preceitos de convívios harmoniosos e segundo padrões de não agressão aos semelhantes.

\section{Ainda recorrendo a Renato Nunes Bittencourt:}

O tipo “idiota” se caracteriza por não se importar com as tramas históricas e políticas vigentes na sua sociedade, pois que o foco de sua atenção psíquica está direcionado para aspectos intensivos de sua própria intimidade afetiva, adotando uma postura existencial reservada, circunstância que desagrada aos costumes morais sustentados por ideários normativos, que em nenhum momento sabe viver a alegria e o amor (BITTENCOURT, 2011a, p. 108).

Como o próprio sofrimento de Jesus até a sua crucificação demonstra, se o idiota não se importa com as questões morais e políticas de sua época ou contrapõe-se a elas por meio de um estilo de vida "desviante", isso não impede que suas atitudes sejam interpretadas pelos líderes políticos como “tomada de partido”. Precisamente por colocar em xeque a lógica política de seu tempo, o Jesus dotado da idiotia e da mais alta pureza d'alma foi punido em um gesto que é político em todas as suas dimensões. 0 que queremos ressaltar, portanto, é que o idiota, aos olhos dos demais, é um ser também político, ainda que não pretendendo sê-lo. Como ressalta Nietzsche, no entanto, os idiotas são raros na história da humanidade, e ele encontra somente um outro exemplar, não nos relatos históricos, mas literários, na figura do Príncipe Míchkin, personagem do livro $O$ idiota, de Dostoiévski (BITTENCOURT, 2011a). A raridade do 
tipo idiota dotado da idiotia nos indica, assim, que prevalece o seu oposto, o tipo do idiota devotado à idiotice, exatamente o contrário da alma generosa voltada ao amor, à alegria e ao reconhecimento do outro.

Adentrar os meandros psicológicos do idiota a partir das pesquisas mais recentes não é o foco de nossa atenção, até porque teríamos que cuidar da perspectiva da idiotia por uma faceta de atraso mental que não é aquela proposta por Nietzsche. Interessa-nos, por outro lado, pensar na idiotia como um polo axiológico que nos auxilia compreensões acerca de tipos humanos pautados pela via da amoralidade positivamente pensada como a negação de valores sociais por eles considerados inadequados, caracterizando os idiotas como sujeitos profundamente comprometidos com princípios éticos de respeito ao outro, dotados de compaixão. Essa, certamente, não é a categoria da maioria dos leitores que comentaram as matérias que abordam as violências de gênero cometidas contra mulheres em relações de proximidade que compõem o corpus que nos desafiou a compreensão acerca de quem, afinal, é capaz de demonstrar tamanho desapreço pelo humano. Passamos, desse modo, da axiologia da idiotia para a da idiotice.

A consulta a qualquer dicionário indicará a figura do idiota como o parvo, o estúpido, o imbecil, um indivíduo destituído de capacidades intelectuais privilegiadas. Há, nessas acepções dicionarizadas que circulam pelo senso comum, a ideia de que o idiota está sempre a promover idiotices, que podem ir de gestos abestalhados sem maiores consequências para si e para os outros até atitudes de efeitos desastrosos, do ponto de vista físico e simbólico, novamente para si e para os outros. Como se nota, a negatividade prevalece em quaisquer circunstâncias que se avalie, no campo da idiotice, os gestos irrefletidos e destituídos de capacidade reflexiva refinada. A essa negatividade, uma outra pode somar-se: quando o idiota se aproxima do tipo humano cujas ações e pensamento - afinal, exceto em casos extremos, o idiota é um ser pensante ao seu modo - são tão largamente disseminadas que colocam em risco o próprio convívio social segundo preceitos, por exemplo, do humanismo.

Produtos dos media são fartos em exemplos de idiotas, alguns a serviço do humor, como o Pateta dos desenhos de Walt Disney, outros a indicar que a idiotice pode ser trágica, como no filme Fargo (1996), dirigido e roteirizado pelos irmãos Joel e Ethan Coen. Se no primeiro caso temos no Pateta um idiota bonachão, amigo de todos e cujas idiotices trazem sempre algum tipo de transtorno sem consequências mais graves, no filme os idiotas são capazes de atrocidades que tiram a vida. Pateta é uma alma destituída 
de maldades, ainda que possa demonstrar ocasionalmente sentimentos como fúria ou inveja, eventualmente magoando seus amigos. No entanto, ele está disposto a pedir sinceras desculpas, até como salvo conduto para novas patetices. Já os tipos idiotas que circulam em Fargo são destituídos de valores éticos e morais comprometidos com a compaixão e o respeito pelo outro. A simulação de sequestro da própria esposa com finalidade de pedir resgate, que se torna sequestro de fato com requintes de crueldade até o assassinato, revela um amplo espectro de idiotas cujas atitudes seriam indesculpáveis, estivessem as personagens imbuídas de espírito para pedir desculpas ou perdão pelos atos de horror que cometeram. Em ambos os casos, no entanto, há um elemento comum, que é a possibilidade de o idiota promover desastres, em graus diversos, a partir de ações pouco refletidas ou fruto de raciocínios tortuosos.

A axiologia da idiotice nos indica, ainda, a proximidade do idiota com o fascista, se tomamos como referência as proposições de Rob Riemen (2012), que busca em tradições filosóficas e políticas a noção do homem-massa, sujeito que, se identificável em qualquer época histórica, constituiria parte considerável das pessoas contemporâneas da ascensão e expansão dos mais variados media, prevalecendo até os dias atuais. Segundo Riemen,

O homem-massa recusa confrontar-se com valores intelectuais e espirituais, já para não falar em deixar-se sobrecarregar por eles. Não há medida, valor ou verdade que the possam ser impostos e que o restrinjam. Para o homem-massa, a vida deve ser sempre fácil e abundante; não reconhece a natureza trágica da existência. Tudo the é permitido pois não existem restrições. 0 esforço intelectual é desnecessário. 0 homem-massa é cheio de si e comporta-se como uma criança mimada. Não está nos seus hábitos escutar, avaliar criticamente as suas opiniões ou ter em conta outras pessoas. Esta atitude reforça nele o sentimento de poder, o desejo de controlar. Só ele e seus congéneres contam, os outros devem adaptar-se. Por conseguinte, tem sempre razão e não precisa de se justificar. Pouco habituado à linguagem da razão e sem vontade de a aprender, só conhece uma linguagem, a do corpo: a violência (RIEMEN, 2012, p. 22-23).

Riemen avalia que o fascismo não está morto, em referência particular à Europa, e que tal se deve ao fato de o continente ter perdido os valores do humanismo que em tese constituiriam o projeto europeu de humanidade. Em contextos culturais outros, como o brasileiro, sociedade que talvez nunca tenha tido o humanismo como centro das suas preocupações morais, éticas e políticas, o “eterno retorno do fascismo”, título do livro de Riemen, que reflete desesperança e alerta, também está presente. A análise dos comentários dos leitores nos indicará, ao menos naquele corpus específico, situação 
preocupante no que tange às características fascistas nos conteúdos segundo a tipologia do homem-massa, protótipo perfeito do fascista, o idiota por excelência que se situa na axiologia da idiotice.

\section{INTERNET, IDIOTICE E COMENTÁRIOS DE LEITORES}

A criação da internet, nos lembra Pierre Lévy (1995), esteve associada aos ideais democráticos de disseminação de informações, configurando uma "tecnologia de inteligência" cujo destino teria a ver não com a perspectiva dos usos que dela se fizesse, mas de projetos políticos acerca das suas potencialidades. Ao negar a perspectiva dos usos, Lévy quer evitar os maniqueísmos típicos dos usos para o bem ou para o mal, com a consequente divisão entre os bons e os maus em cada polo das modalidades usuárias. Em outros termos, para além da dimensão dos usos, é necessário verificar o cenário em que eles se dão. Como sociotécnica, a internet é a confluência de avanços tecnológicos e de suas permanentes reapropriações e reconfigurações pela sociedade, o que a situa potencialmente tanto útil a projetos de democratização, como àqueles de controle e centralização.

Pois é ainda na dimensão sociotécnica que, junto a aquelas preocupações iniciais acerca das potencialidades democratizantes da internet, crescentemente são apontadas outras dimensões preocupantes, tais como o controle econômico da rede a partir de empresas responsáveis por softwares e outras soluções tecnológicas - do design aos programas, dos aplicativos às redes sociais, dos provedores aos demais modelos de negócios que ela proporciona. Ao problema da censura e do controle político-ideológico imposto por governantes, somam-se preocupações não menos relevantes com a privacidade, agora não somente referente aos potenciais de vigilância e controle pelo Estado, mas pelas grandes corporações que controlam contas de e-mails, redes sociais e demais instrumentos e processos que têm a rede como locus de realização.

Tal como encontramos em estudos mais recentes, ao conjunto de variáveis descritas acima, soma-se o planejamento algorítmico (FERRAZ; SAINT CLAIR, 2019), com o direcionamento de conteúdos que favorecem a formação de bolhas de opinião, quando não a indução de pontos de vista por programações de difícil compreensão e controle. No universo dos comentários de internet, a presença de robôs que disseminam agressões, e mesmo as produzem a partir de programação algorítmica, é outra realidade complexa, 
que inclusive acrescenta componentes não diretamente humanos - embora por eles controlados - ao universo dos idiotas pertencentes ao polo axiológico da idiotice.

Um conjunto amplo de reflexões sobre intolerâncias, discursos de ódio e outras modalidades de violências físicas e simbólicas que circulam na internet (BERTOLINI, 2016; CARVALHO, 2016; PENACHIONI, GUISORDI, PRADA, 2016) é indicativo da dimensão do que aqui propomos refletir em torno da axiologia do idiota. Desse modo, a própria ação dos robôs deve ser vista como a talvez mais eficiente ação humana de controle algorítmico com vistas ao espraiamento de fake news, parte da estratégia de desqualificação e de destruição de reputações por meio de processos que se dão no atual contexto de polarizações políticas e ideológicas, com a ascensão da extrema-direita a postos de comando em governos pelo mundo afora, como temos no Brasil com Jair Bolsonaro.

Sob a perspectiva da compreensão da potencial toxicidade das redes sociais e da internet como um todo, diversas são as pesquisas centradas em reflexões sobre relações de gênero, racismo, xenofobia e outras manifestações de preconceito e violências físicas e simbólicas contra mulheres, pessoas negras, migrantes e populações de lésbicas, gays, bissexuais, travestis, transexuais e intersex (LGBTI). Tais investigações têm voltado a atenção para comentários degradantes na internet sobre notícias, postagens em redes sociais e outras modalidades de interação on-line. Jessica Megarry (2014), em pesquisa sobre incivilidade on-line e assédio contra mulheres, investigou postagens a partir da hashtag \#mencallmethings e concluiu que

O dano do assédio sexual on-line pode ser visto como mais amplo do que o sofrido por uma mulher: ele impede a participação das mulheres na conscientização feminista e sugere as limitações do ativismo feminista no contexto on-line. No entanto, a internet está criando um registro público das experiências on-line das mulheres, e, talvez pela primeira vez na história, o silenciamento e o assédio das mulheres estão sendo permanentemente documentados. As plataformas on-line de mídias sociais, portanto, fornecem um recurso vibrante para análise por cientistas sociais e criam uma oportunidade única para desafiar e revelar a extensão da dominância social masculina na esfera pública (MEGARRY, 2014, p. 53, tradução nossa).

Comentários de leitores na internet constituem, pois, um vasto campo para investigações sociais no que diz respeito a manifestações de ódio, de incivilidade, de intolerâncias, de preconceitos e outras estratégias de inferiorização. Contudo, é necessário não os situar apenas na esfera das sociabilidades e estratégias comunicacionais on-line, posto que, a despeito de robôs no universo da internet, assassinatos, injúrias e agressões físicas e simbólicas de diversos graus e extensão são cotidianamente 
registrados contra mulheres, especialmente no Brasil, como indicamos na sequência. É importante ressaltar que as potencialidades da internet para o combate às estratégias de ódio, preconceitos, incivilidades e intolerâncias se encontram abertas e têm sido aproveitadas, o que transforma o ambiente on-line em um campo de disputas de sentido e de jogos de poder.

\section{A IDIOTICE MANIFESTA NOS COMENTÁRIOS SOBRE NOTÍCIAS DE CRIMES CONTRA MULHERES}

Para uma melhor compreensão da natureza idiota dos comentadores sobre notícias relativas a crimes de proximidade contra mulheres motivadas por relações de gênero, é indispensável ao menos uma breve indicação das condições em que as violências ocorrem. Como estudos sobre relações de gênero denunciam, os pressupostos machistas e misóginos que marcam as relações de gênero criaram falsas hierarquias, fundadas em pressupostos igualmente falsos de que as mulheres são inferiores aos homens (BUTLER, 2007, 2008; CARVALHO, 2012; LOURO, 2004), gerando, na esteira, as mais variadas formas de violências físicas e simbólicas.

Vistas sob o prisma das violências físicas e simbólicas genericamente atribuídas às relações de gênero, ou nas especificidades do feminicídio (PASINATO, 2011) - assassinatos que têm motivação exclusiva no fato de serem mortas porque mulheres, acentuando a natureza das hierarquias genderizadas -, os crimes contra mulheres constituíram o corpus de narrativas jornalísticas das quais retiramos os comentários de leitores. Durante dois meses - fins de fevereiro a fins de abril de 2015 - foram coletadas narrativas nos sítios do UOL, brasileiro, e do jornal Público, português, com o recorte sobre narrativas de crimes de proximidade contra mulheres em relações de gênero, com a preocupação adicional de não restringir a noção de proximidade àquela classicamente compreendida segundo a lógica do parentesco (maridos, filhos, pais, primos e padrastos), namorados, ex-companheiros e vizinhos. Perseguindo a lógica de que em sociedades complexas e de risco (BECK, 1997; GIDDENS, 1991) as relações de proximidade ocorrem também por relações de confiança que levam a diferentes modalidades de proximidade, entendemos que colegas de trabalho, de atividades religiosas, prestadores de serviços domésticos, operadores de transportes públicos, agentes policiais e de segurança, dentre outras categorias, são também vitimizadores de mulheres a partir de laços de proximidade que, se não estão dados por parentesco, relações de afeto ou de vizinhança, constituem, 
ainda assim, grupos de convívio cotidiano aos quais as mulheres são obrigatoriamente expostas, inclusive a partir da lógica que Antony Giddens (1991) define como a confiança nos sistemas peritos. Considerá-los como de proximidade por necessidades diversas de sociabilidade e solução de problemas práticos do dia-a-dia é simultaneamente reconhecer que, sem a confiança socialmente construída ao menos como hipótese, seria difícil enfrentar uma série de desafios de ordem prática, mas também espiritual, como as atividades religiosas e as de aprendizado escolar. A confiança, como acentuou Niklas Luhmann (1996), constitui uma inevitabilidade social e individual, já que não confiar inviabilizaria qualquer forma de convívio e de organização em sociedade. Ainda que confiando a partir da suspeita de que a confiança seja frágil, a desconfiança não pode ser generalizada.

Outra preocupação relativa à definição dos crimes de proximidade contra mulheres em relações de gênero foi evitar abordá-los a partir da premissa de crimes passionais ou por vingança. A noção dos crimes passionais serviu, ao menos no caso brasileiro, para atenuar, inclusive juridicamente, a gravidade do ato criminoso, não raramente associado ainda ao pressuposto de "lavar a honra" do macho ofendido. Sobre os problemas inerentes à noção de crimes passionais, Bárbara Lopes Caldeira destaca, ao analisar notícias que recorrem a este conceito, que

\begin{abstract}
Muitas [violências] são, inclusive, tomadas como residuais de "crimes passionais" ressaltando uma carga de emoção que parece dizer: "o homem que cometeu o ato de violência estava fora de si”. A noção da passionalidade, inclusive, é, de antemão, extremamente problemática. De acordo com a autora Isabelle Delpla (2015), “insistir na paixão é descartar as dimensões sociais, institucionais e econômicas da violência” (p.303), deixando, assim, de problematizá-la (CALDEIRA, 2017, p. 12).
\end{abstract}

Pois são precisamente as lógicas das relações de gênero que têm representado as dimensões sociais das múltiplas violências físicas e simbólicas contra mulheres. A perspectiva de vingança nos crimes físicos e simbólicos carrega consigo a ideia de ato naturalizado por sentimento que estaria despido de outra motivação que não a própria vingança como "gesto reparador" de algum mal que vitimizou o agressor. Em outros termos, pode transformar o algoz em vítima que, tal como no crime passional, não teve alternativa diferente de reparar a injustiça de que foi alvo. Nos dois casos apagam-se, pela naturalização, as relações de gênero que motivam verdadeiramente os crimes, afinal, assentados na falsa lógica da superioridade masculina e da inferioridade física e moral das mulheres. 
Em que pesem as diferenças socioculturais que marcam as sociedades brasileira e portuguesa - de grande monta e que não conseguiríamos adequadamente indicar nesse texto - é possível dizer que o machismo e a misoginia estão presentes nos dois países. Essa convicção se reforça, inclusive, na amostra de narrativas jornalísticas sobre crimes de proximidade cometidos contra mulheres em relações de gênero cujos comentários de leitores estamos a investigar. Algumas diferenças, no entanto, são indicadoras de especificidades, abrangendo o tratamento jurídico dispensado ao problema, que constitui grave questão política a desafiar governos, organizações governamentais internacionais e entidades não governamentais diversas.

No Brasil, as violências de gênero contra mulheres, identificadas ou não como crimes de proximidade, são geralmente tratadas - o que inclui os levantamentos estatísticos - a partir das especificidades desses crimes. Desse modo, os dados estatísticos mais abrangentes tornados públicos são produzidos pelo serviço "Ligue 180", disponibilizado a mulheres brasileiras em território nacional e em alguns países, que recebe denúncias de violências físicas e simbólicas diversas, de tráfico humano, exploração sexual e outras modalidades de maus tratos (SPM, 2014, 2015). Os dados coletados, no entanto, não permitem um mapa completo das violências sofridas por mulheres brasileiras, ainda que sejam importantes na definição de políticas governamentais e outras iniciativas de enfrentamento do problema. Dentre outros limites, os dados não contemplam os oficializados pelas autoridades policiais responsáveis pelo registro de crimes diversos contra mulheres. Legalmente os crimes contra mulheres no Brasil estão previstos, com suas respectivas punições, em duas legislações especialmente aprovadas com essa finaLidade: a Lei Maria da Penha (BRASIL, 2006) e a Lei do Feminicídio (BRASIL, 2015), de modo que é possível afirmar que a legislação brasileira reflete preocupações em certa medida comuns à América Latina.

Em Portugal os levantamentos estatísticos sobre violências contra mulheres (APAV, 2014) são realizados por uma entidade não governamental a partir, no entanto, de dados coletados junto a órgãos dos poderes Executivo e Judiciário e suas instituições policiais. Diferentemente do Brasil, os dados são destacados do conjunto de violências gerais cometidas contra as pessoas. Não por acaso, os dados são consolidados pela Associação Portuguesa de Apoio à Vítima (Apav), em cujos relatórios estão outras modalidades de violências, inclusive patrimoniais, e não somente contra mulheres, que abrangem toda a população portuguesa. Não é possível, assim como no caso brasileiro, indicar se os 
dados da Apav refletem a realidade da violência contra mulheres em Portugal, assim como eles não indicam especificidades dos crimes de proximidade, à semelhança do Brasil. Outra diferença entre os dois países está na preocupação, em Portugal, com a violência nos namoros, inclusive em contexto escolar, dado que no Brasil merece pouca atenção. No que diz respeito aos aspectos legais, a grande diferença está na forma de promoção de legislações que não tratam das especificidades dos crimes contra mulheres tal como a legislação brasileira, o que não significa que eles são ignorados ou negligenciados juridicamente. Portugal adota, relativamente aos crimes contra mulheres, a lógica da legislação da Comunidade Europeia, permitindo punições específicas, sem promover leis como as referidas brasileiras.

Ainda que esteja longe de constituir um cenário comportamental e legal das especificidades no entorno das violências de gênero contra mulheres em crimes de proximidade no Brasil e em Portugal, os dados apresentados indicam ser este tema de elevada complexidade que, por conseguinte, impõe desafios à própria cobertura jornalística. Em relação a esses desafios, não entraremos em detalhes, privilegiando os comentários de leitores. Mantendo a lógica de um mínimo de contextualização, apresentamos brevemente as condições de produção noticiosa do UOL e do Público, dois sítios identificados com o jornalismo de referência e importantes do ponto de vista da audiência nos respectivos países. O UOL faz parte de um grupo de comunicação com outros media, como a Folha de S.Paulo, jornal do qual reproduz parte do conteúdo, além de publicar notícias de uma série de emissoras de televisão e de rádio, de jornais e revistas impressos e eletrônicos e de agências de notícias brasileiras e estrangeiras. Trata-se, portanto, de sítio que conta, além de equipe de reportagem própria, com noticiários vindos de uma variada gama de media. Já o Público divulga somente notícias produzidas por sua própria equipe de reportagem e de agências de notícias portuguesas e estrangeiras, em número bem menor de origem das informações em comparação ao UOL.

Quando consideramos as especificidades dos dois sítios e o fato de Portugal possuir cerca de $5 \%$ da população brasileira, as diferenças nos totais de notícias publicadas em cada um são pequenas. Enquanto o UOL publicou 38 matérias que abordam crimes de proximidade contra mulheres em relações de gênero, o Público publicou 26. A diferença que chama atenção fica por conta dos comentários de leitores: 815 no UOL e 112 no Público. É importante ressaltar que, apesar de os dois sítios indicarem políticas de mediação e controle dos comentários, somente o Público faz valer essas 
prerrogativas, interrompendo-os quando considera que os conteúdos ultrapassam os limites impostos pela política de comentários. Em parte, essa pode ser uma explicação para as diferenças nos totais de comentários, assim como para o fato de, proporcionalmente, o sítio português apresentar menor número de notícias comentadas. As narrativas que geraram os comentários trataram de diversos acontecimentos referentes aos crimes de proximidade contra mulheres em relações de gênero: assassinatos por maridos ou ex-maridos, assassinato de filho em comum pelo marido para vingar a separação da esposa, violências físicas e simbólicas diversas, assédio sexual, assédio moral, campanhas de prevenção a tais crimes, aprovação de legislação que os combata, dentre outras variações em torno dessas temáticas. A coleta não ficou restrita aos casos ocorridos no Brasil e em Portugal, ainda que seja pouco significativo o número daqueles ocorridos em outros países.

O que chamamos de comentários de idiotas, segundo a axiologia da idiotice? Partimos do pressuposto de que os comentários que se encaixam nessa definição são aqueles que revelam preconceitos de gênero e indicam, por consequência, posturas machistas e misóginas. Porém, incluímos também comentários e comentadores que revelem outras formas de preconceito, intolerância e cultura da violência, no último caso, alcançando, por exemplo, a desqualificação de instrumentos jurídicos e a defesa da pena de morte como solução para os crimes. Ao reproduzirmos dois desses comentários, parece-nos que os próprios termos em que foram produzidos ajudarão a explicitar a presença da axiologia da idiotice segundo a lógica que apresentamos. São comentários que deixam à mostra o desprezo por valores identificados com o humanismo. Ainda a destacar que nos comentários de leitores brasileiros notamos, em sete matérias, posição hegemônica favorável aos agressores, número que é zero nos comentários portugueses. Também foi zero o número de matérias portuguesas com maioria de comentários de leitores hegemonicamente desfavoráveis às vítimas, ao passo que encontramos 15 matérias nas quais os comentários de leitores brasileiros seguem essa postura de modo majoritário. Esses números, por si só, nos ajudam a compreender a ética do idiota segundo a axiologia da idiotice.

Os comentários serão reproduzidos com a mesma forma gráfica e redação originais, pois elas são componentes da própria lógica da idiotice, ao revelarem, por desprezo pela escrita segundo as normas gramaticais e uso de imagens e nicknames associados a variadas formas de violência, traços da axiologia do idiota em sua acepção negativa. 
Não nos preocupamos em tentar identificar se algum comentário poderia ter sido produzido por robô, considerando que em tal hipótese os algoritmos que os comanda são guiados por princípios humanos.

O comentário brasileiro que destacamos é sobre a notícia “Vídeo mostra mulheres agredindo garçons” (MACHADO, 2015). A narrativa informa sobre um vídeo que circulava pelo aplicativo WhatsApp, no qual mulheres aparecem agredindo garçons de um bar situado na cidade paranaense de Cascavel após serem expulsas do local sob acusações de que estariam bêbadas e de terem queimado cadeiras com cinzas de narguilé e uma delas levantado a blusa e recebido carícias nos seios feitas por outra companheira. 0 texto traz indícios de lesbofobia, pois uma das razões para a expulsão seria a troca de carícias entre mulheres, e recebeu 84 comentários, a maioria de teor machista e misógino, mesclando preconceitos contra pessoas gordas e defendendo a volta de governos militares ao Brasil, como se uma ditadura pudesse impedir acontecimentos como o informado pela notícia. Ainda na linha de comentários políticos, há uma série de posicionamentos contrários à Lei Maria da Penha, segundo a lógica de que ela legitima mentiras de mulheres e vitimizam os homens, invertendo a realidade das violências masculinas cometidas contra mulheres brasileiras. Um comentarista, inclusive, jocosamente propôs uma lei Hélio de la Peña, humorista brasileiro cujo sobrenome seria o correspondente em castelhano ao de Maria da Penha, a brasileira cuja luta em defesa das mulheres levou à nomeação da lei que visa proteger e prevenir crimes motivados por machismo e misoginia. Maria da Penha sofreu agressões contínuas de seu ex-marido, que a deixou em cadeira de rodas.

Em um dos comentários, o leitor identificado como Roberto Macedo (não há imagem acompanhando o nickname), diz que "não passa de duas biscates, se eu tivesse lá teria dado um murro na cara dessa vadia que ela estaria procurando o rumo até agora, puta é puta”. A promessa de agressão física contra as mulheres soma-se a depreciações simbólicas na afirmação de que seriam "duas biscates", no contexto do comentário indicando pessoas inferiores, além da atribuição de prostitutas. Exemplo paradigmático do tipo de comentários que predomina na amostra que recolhemos, o posicionamento exposto nos indica que o idiota segundo a axiologia da idiotice se aproxima do tipo fascista que, como vimos a partir de Rob Riemen, é alguém pouco afeito ao exercício intelectual, repetindo posições que substituem a reflexão por atos 
de violências físicas e simbólicas, preferencialmente contra algum inimigo eleito, no caso da nossa pesquisa, as mulheres.

Do lado português, temos o comentário sobre notícia informando o assassinato pelo pai do próprio filho como vingança contra a companheira, após uma discussão ao telefone. Sob a assinatura João, acompanhada da imagem de um felino de aparência agressiva, o comentador sustenta: "Pena de morte para esta besta. Não vale a pena o estado estar a sustentar este animal durante os anos de pena. Estou a ver é que está uns dez anos preso e depois volta cá para fora". Os comentários sobre a notícia "Bebé terá sido morto à facada pelo pai em Oeiras" (DIAS, 2015) foram dos mais abundantes encontrados no Público, ocupando quatro páginas, com fotos ou ilustrações, para uma página, sem foto ou ilustração, dedicada à notícia. Embora menos agressivo que o comentário brasileiro, por não se propor a agredir fisicamente alguém e por preservar a mulher de ofensas, a perspectiva da solução simples pela aplicação da pena de morte repete método comum que substitui a reflexão sobre as motivações de crimes de gênero por fórmulas que se aplicariam a punições de qualquer categoria de crime. Soluções violentas para problemas de violência, especialmente quando tão radicais quanto a pena de morte, são também típicas da ausência de argumentos sofisticados, na mesma lógica do tipo de raciocínio do fascista prototípico.

Vários outros exemplos poderiam ser utilizados, mas tenderiam a repetir os padrões que aqui delineamos, mais a título de ilustração do que de exaustão estatística comprobatória de uma tese. É preciso destacar que não temos somente comentários nessa linha, inclusive com alguns que se contrapõem aos comentários feitos pelos dotados da idiotice. A tipificação do idiota segundo a axiologia da idiotice, em nossa amostra, como indicamos, não se dá somente relativamente aos conteúdos, mas também na escolha de imagens que acompanham os nicknames, e mesmo nestes. São comuns imagens de pessoas portando armas e de personagens dos media identificados com a violência associadas ou não a nicknames que podem trazer referências explícitas a armas letais, como a Winchester, famosa marca de revólveres adotada como apelido por uma comentadora.

Outra estratégia do idiota comentador de internet é o anonimato, pois, mesmo quando há assinatura que sugere o verdadeiro nome de quem comenta, não há garantia de que efetivamente estamos diante de alguém que assume publicamente sua identidade. 
A atitude covarde de não se assumir enquanto tal é também um traço que podemos associar ao fascista.

\section{CONSIDERAÇÕES FINAIS}

Ao analisarem coberturas noticiosas e suas repercussões na internet pela ótica do biopoder, Henrique Antoun e Fábio Malini consideram que um dos maiores temores do bipoder em sua configuração on-line está na possibilidade de questionamento das posições adotadas pelas grandes corporações dos media. Nessa perspectiva,

Este geralmente tem a função de revelar não somente omissões, mas as posições políticas, históricas e de classe do poder em rede. Não é à toa que os mídias tradicionais só liberam comentários naquelas reportagens que agitam os fascistas ou acalmam os ingênuos. A partir do momento que o comentário ganha mais audiência do que a própria agenda midiática, as mídias são forçadas a mencioná-los, quando não investigá-los (ANTOUN; MALINI, 2010, p. 292).

Não lidamos com as repercussões dos comentários de leitores nem com a possibilidade de eles "agendarem" os media. No entanto, as proposições de Henrique Antoun e Fábio Malini nos auxiliam a compreender que não parece aleatória a quantidade de comentadores que representam os típicos idiotas segundo a axiologia da idiotice. Liberar ou permitir comentários agressivos, sugere nossa amostra, é parte de estratégias dos media, por razões que exigem esforços de pesquisa distintos dos que adotamos. Longe de configurar censura ou limite à liberdade de expressão, a mediação pelos sítios que evite manifestações de idiotia constitui exercício que, afinal, liberaria os próprios media da compactuação com a lógica do idiota, colaborando para evitar crimes de opinião. Nesse sentido, o Público mostra-se mais sensível ao problema dos comentários idiotas do que o UOL, que, em momento algum, indica agir de forma eficiente no que tange à mediação dos comentários. Se voltamos à pergunta capciosa feita a Umberto Eco e que nos serviu de inspiração inicial, a mediação dos comentários não é um controle que limita a liberdade de expressão ou uma modalidade de restrição de críticas qualificadas e livres da axiologia da idiotice; certamente, a internet deve ser regulada segundo pressupostos de respeito a princípios legais que preservem reputações e impeçam a disseminação de ódios, preconceitos e outras manifestações de idiotice e de atitudes fascistas.

O convívio na democracia e na pluralidade é avesso ao desejo de idiotas dotados da axiologia da idiotice, quando não também fascistas. Nessa perspectiva, Moisés Lemos Martins, ao tratar do trágico na modernidade, nos oferece uma preciosa reflexão: 
A dissociação entre o ideal democrático e aqueles que deixaram de o habitar rasga lentamente o tecido da nossa cultura. Uma espécie de irracionalidade colectiva multiplica nas instituições os homens exilados do espírito - exilados afinal da única coisa que tornaria credíveis os seus poderes. Emigra o espírito, emigra a adesão dos cidadãos. Vence o indiferentismo e o absentismo (MARTINS, 2002, p. 5).

Ao menos no corpus de comentários de leitores de internet sobre o qual nos debruçamos, eis a realidade identificada. Não é de esperar, pela própria raridade notada por Nietzsche, que prevaleçam entre os comentadores de internet o idiota segundo a axiologia da idiotia, capaz de compaixão a partir do respeito pelo outro. Considerando que a imperfeição humana, no entanto, só pode ser superada pelo exercício do convívio na pluralidade e no respeito às diferenças livre de ranços como aqueles identificados com as relações de gênero que forjam violências e crimes contra mulheres - mas não somente contra elas -, aos media cabe a função de evitar que seus espaços sejam ocupados pela espécie do idiota situado na axiologia da idiotice.

Importante ainda destacar, seguindo as proposições de Rita Laura Segato (2016), que as violências físicas e simbólicas contra mulheres constituem modernamente um tipo específico de guerra que alcança níveis elevados de sofisticada crueldade por meio do Estado, mas também de uma diversidade de agentes não abrigados diretamente pelas estruturas do poder estatal. A lógica axiológica da idiotice tem nas violências físicas e simbólicas contra mulheres campo fértil para a sua manifestação e expansão. No entanto, ela tem levado também a ações em sentido contrário, em que mulheres e pessoas a elas aliadas crescentemente elaboram estratégias de enfrentamento à idiotice e à sua axiologia perversa.

\section{FINANCIAMENTOS}

No Brasil, Coordenação de Aperfeiçoamento de Pessoal de Nível Superior (Capes), Conselho Nacional de Desenvolvimento Científico e Tecnológico (CNPq) e Fundação de Amparo à Pesquisa do Estado de Minas Gerais (Fapemig); em Portugal, Fundação para a Ciência e a Tecnologia (FCT).

\section{BIBLIOGRAFIA}

ANTOUN, Henrique; MALINI, Fábio. Ontologia da liberdade na rede: a guerra das narrativas na internet e a luta social na democracia. Revista Famecos, Porto Alegre, v. 17, n. 3, p. 286-294, 2010. Disponível 
em: http: / / revistaseletronicas.pucrs.br/ojs/index.php/revistafamecos/article/view/8196/5885. Acesso em: 20 maio 2015.

ASSOCIAÇÃO PORTUGUESA DE APOIO À VÍTIMA - APAV. Estatísticas Apav: relatório anual 2014. Disponível em: http://www.apav.pt/apav_v2/images/pdf/Estatisticas_APAV_Relatorio_Anual_2014.pdf. Acesso em: 26 maio 2015.

BECK, Ulrich. A reinvenção da política: rumo a uma teoria da modernização reflexiva. In: BECK, Ulrich; GIDDENS, Anthony; LASCH, Scott. Modernização reflexiva: política, tradição e estética na ordem social moderna. São Paulo: Editora da Universidade Estadual Paulista, 1997.

BERTOLINI, Jeferson. A banalidade do mal na internet: aplicando Arendt, Nietzsche e Hobbes para pensar comentários políticos agressivos. Temática, João Pessoa, ano 12, n. 8, p. 17-31, ago. 2016. Disponível em: https://periodicos.ufpb.br/ojs2/index.php/tematica/article/view/30086/15918. Acesso em: 15 jun. 2020.

BITTENCOURT, Renato Nunes. A psicologia da idiotia em Dostoiévski e Nietzsche. AdVerbum, Limeira, v. 6, n. 1, p. 103-120, 2011a. Disponível em: http://www.psicanaliseefilosofia.com.br/adverbum/vol6_ 1/06_01_08psicologiadostoievski.pdf. Acesso em: 20 maio 2015.

BITTENCOURT, Renato Nunes. Nietzsche e a idiotia divina de Jesus. Kriterion, Belo Horizonte, vol. 52, n. 123, p. 105-119, 2011b. Disponível em: http://www.scielo.br/pdf/kr/v52n123/a06v52n123.pdf. Acesso em: 20 maio 2015.

BRASIL. Lei n 11.340, de 7 de agosto de 2006. Diário Oficial da União, Brasília, DF, 8 ago. 2006. p. 1. Disponível em: http://www.planalto.gov.br/ccivil_03/_ato2004-2006/2006/lei/l11340.htm. Acesso em: 26 maio 2015.

BRASIL. Lei n 13.104, de 9 de março de 2015. Diário Oficial da União, Brasília, DF, 10 mar. 2015. p. 1. Disponível em: http://www.planalto.gov.br/ccivil_03/_Ato2015-2018/2015/Lei/L13104.htm. Acesso em: 26 maio 2015.

BUTLER, Judith. Corpos que pesam: sobre os limites discursivos do “sexo”. In: LOURO, Guacira Lopes (org.). O corpo educado: pedagogias da sexualidade. Belo Horizonte: Autêntica, 2007.

BUTLER, Judith. Problemas de gênero: feminismo e subversão da identidade. Rio de Janeiro: Civilização Brasileira, 2008.

CALDEIRA, Bárbara Lopes. Entre assassinatos em série e uma série de assassinatos: o tecer da intriga nas construções narrativas de mulheres mortas e seus agressores nas páginas de dois impressos mineiros. Dissertação (Mestrado em Comunicação Social) - Programa de Pós-Graduação em Comunicação Social, Universidade Feral de Minas Gerais, Belo Horizonte, 2017.

CARVALHO, Carlos Alberto de. Jornalismo, homofobia e relações de gênero. Curitiba: Appris, 2012. 
CARVALHO, Carlos Alberto de. Banalidade do mal em comentários de leitores: internet e disseminação da intolerância. E-Compós, Brasília, v. 19, n. 2., p. 1-18, 2016. Disponível em: https://www.e-compos. org.br/e-compos/article/view/1246. Acesso em: 15 jun. 2020.

CHAPARRO, Manuel Carlos. As duas faces de Umberto Eco. Observatório da Imprensa, São Paulo, 3 jul. 2015. Disponível em: http://www.observatoriodaimprensa.com.br/jornal-de-debates/as-duasfaces-de-umberto-eco/. Acesso em: 11 dez. 2020.

DIAS, Pedro Sales. Bebé terá sido morto à facada pelo pai em Oeiras. Público, Lisboa, 8 abr. 2015. Disponível em: http://www.publico.pt/sociedade/noticia/bebe-tera-sido-morto-a-facada-pelo-pai-emlisboa-1691770. Acesso em: 8 abr. 2015.

ECO, Umberto. Umberto Eco abandona as sinfonias de Mahler e opta pelo jazz de Charlie Parker. [Entrevista cedida a João Céu e Silva]. Diário de Notícias, Lisboa, 24 maio 2015.

FARGO: a homespun morder story. Direção: Joel e Ethan Coen. Los Angeles: Fox Home Entertainment, 1996. 1 DVD (98 $\mathrm{min})$, DTS 6.1, color.

FERRAZ, Maria Cristina Franco; SAINT CLAIR, Ericson. Por uma genealogia do ódio online: contágio, viralização e ressentimento. Matrizes, São Paulo, v. 13, n. 1, 2019. DOI 10.11606/issn.1982-8160. v13i1p133-147. Acesso em: 15 abr. 2020.

GIDDENS, Anthony. As consequências da modernidade. São Paulo: Editora da Universidade Estadual Paulista, 1991.

LÉVY, Pierre. As tecnologias da inteligência: o futuro do pensamento na era da informática. Rio de Janeiro: Editora 34, 1995.

LOURO, Guacira Lopes. Um corpo estranho: ensaios sobre sexualidade e teoria queer. Belo Horizonte: Autêntica, 2004.

LUHMANN, Niklas. Confianza. Barcelona: Anthropos, 1996.

MACHADO, Allan. Vídeo mostra mulheres agredindo garçons. CGN, Cascavel, 10 mar. 2015. Disponível em: http://cgn.uol.com.br/noticia/127413/video-mostra-mulheres-agredindo-garcons. Acesso em: 10 mar. 2015.

MARTINS, Moisés de Lemos. 0 trágico na modernidade. Interact: revista on-line de arte, cultura e tecnologia, Lisboa, n. 5, mar. 2002. Disponível em: http://repositorium.sdum.uminho.pt/ bitstream/1822/1087/1/mmartins_Tragico_2002.pdf. Acesso em: 26 maio 2015.

MEGARRY, Jessica. Online incivility or sexual harassment? Conceptualising women's experiences in the digital age. Women's Studies International Forum, Amsterdam, v. 47, p. 46-55, 2014. Doi: 10.1016/j. wsif.2014.07.012. Acesso em: 26 maio 2015. 
NIETZSCHE, Friedrich. O anticristo. Covilhã: Lusosofia, s/d.

PASINATO, Wânia. “Femicídios” e as mortes de mulheres no Brasil. Cadernos Pagu, Campinas, n. 37, p. 219-246, dez. 2011. Disponível em http://www.scielo.br/scielo.php?script=sci_arttext\&pid=S0104$83332011000200008 \& \operatorname{lng}=$ pt\&nrm=iso. Acesso em: 10 abril 2014.

PENACHIONI, Julia; GUISORDI, Patricia Cucio; PRADA, Thiago. A banalidade do mal na atualidade: as redes sociais online como espaços de guerra. Aurora: revista de arte, mídia e política, São Paulo, v. 9, n. 25, p. 76-96, 2016. Acesso em: 15 abr. 2020.

RIEMEN, Rob. O eterno retorno do fascismo. Lisboa: Bizâncio, 2012.

SECRETARIA DE POLÍTICAS PARA AS MULHERES - SPM. Ligue 180: Balanço 2014. Brasília, DF: SPM, 2015. Disponível em: https://www.gov.br/mdh/pt-br/centrais-de-conteudo/ligue-180/balancoligue-180-2014.pdf/view. Acesso em: 26 maio 2015.

SECRETARIA DE POLÍTICAS PARAS AS MULHERES - SPM. Ligue 180: Balanço 2015. Brasília, DF: SPM, 2016. Disponível em: https://www.gov.br/mdh/pt-br/centrais-de-conteudo/ligue-180/balancoligue-180-2015.pdf. Acesso em: 26 maio 2015.

SEGATO, Rita Laura. La guerra contra las mujeres. Madrid: Traficantes de Sueños, 2016.

SILVESTRE, Paulo. Desculpe, Umberto Eco. Estado de S. Paulo, São Paulo, 27 maio 2020. Disponível em: https://brasil.estadao.com.br/blogs/macaco-eletrico/desculpe-umberto-eco/. Acesso em 11 dez. 2020.

Artigo recebido em: 6 de julho de 2019 .

Artigo aceito em: 23 de maio de 2021 . 